\title{
Sound barriers to enable open windows and integration in landscape
}

\author{
G. Rosenhouse \\ Faculty of Civil Engineering - Technion, Haifa, Israel
}

\begin{abstract}
Sound barriers are a familiar sight along highways. They act to reduce noise levels in residential areas. As architectural elements that influence the environmental view, sound barriers form a variety of kinds of geometrical shapes, textures, and colour combinations, and they are made of different building materials, such as concrete, plastics (including transparent panels), glass, wood etc. A part of the sound barriers is designed to be impressive, having a strong architectural effect on the landscape. Yet another extreme is possible - merging with the environment. This paper illustrates a diversity of solutions that make part of the environment, and are not significant visually, or at least minimize the intervention in nature. Examples of such designs that are shown here are chosen from a variety that includes the moderate slope barrier, the local screening, the combination of earth berms with walls, lowered roads, hidden walls, walls with end absorption and non planar walls.
\end{abstract}

\section{Introduction}

Residential areas near highways, railway lines, airports, industrial premises, recreation areas and other noisy zones are often subject to excessive noise levels, which are beyond the standards limits. Such situations invite acoustic treatment as to reduce the noise levels at noise-sensitive points to acceptable levels. The solutions can be divided into two distinct categories, namely:

1. External screening such as long sound barrier walls along noisy roads.

2. Acoustic isolation of the receiver, such as double glazed acoustic closed windows, or adding air conditioning and acoustic absorption to rooms exposed to noise. In some cases, also combined with acoustic isolation of the source. 
While the first type may intervene in natural landscape the second one forces people to live in sealed rooms, where direct flow of fresh air is avoided (It should be noted that it is also possible to use ventilation units combined with noise silencers and air cleaning devices, but even then the feeling of open windows is prevented).

The need to close windows, which necessitates in turn the use of air conditioning leads also to a significant waste of energy. Yet, the usual low sound barriers (up to $5 \mathrm{~m}$ high) cannot screen the upper floors in a high rise building, unless local screening is built over the front of the protected building.

A useful observation is that most of the length of highways, for example, passes near rural areas, where typically building height does not exceed two floors. However, in such areas the speed of the cars is very high, which increases the noise level considerably. Planning sound barriers combined with consideration of the topographic conditions can be useful in this case.

Regular thin walled sound barriers do not integrate well with local landscapes. For that reason architects of such walls decorate them by using different shapes, materials (including transparent panels) and colours. This solution is not natural, and there exist solutions to the problem. In this paper we show schemes and approaches that integrate environment as it is.

\section{Theory}

A rigid screen that separates between the noise source $\mathrm{S}$ and the receiver $\mathrm{P}$ and intercepts the sight line SP causes reduction of noise levels at P. The sound barrier can-not entirely avoid the penetration of noise into the "shadow zone" due to diffraction at the edges of the screen, taking into account an approximation of infinite transmission loss through the wall.

The most fundamental model of the environmental sound barrier is the rigid, thin half plane (see Figure 1) and several theories have been developed in order to find how much noise reduction is achieved by it. The most popular concept of solving the diffraction pattern caused by the wall is that it combines a superposition of the waves scattered by the edge of the plane and the part of the incident waves that is not blocked by the screen. This idea was first brought into consideration in the $18^{\text {th }}$ century by Young and Fresnel, and had a rigorous mathematical solution for a 2-D problem and a plane wave first introduced by Sommerfeld [1]. During the years, the theory was further developed, generalized, and has obtained integral forms, and applied the use of Wiener-Hopf method. Tolstoy [2] obtained an exact explicit solution for the sound diffracted by a wedge, represented by a sum of infinite series. For a review of other solution methods, see Maekawa [3], Pierce [4], Hu and Wong [5], Menounou et al. [6], Menounou [7], Quis [8], Li and Wong [9], among many others.

The simplest solution for noise reduction by a thin half plane that fits the diffraction approximation model of Fresnel-Kirchhoff was presented by Maekawa [3], although this approach was already known (See Redfearn [10]), Rettinger [11-13]), and its fundamental physical model was borrowed from optics (Born and Wolf [14]. Maekawa's Formula reads: 


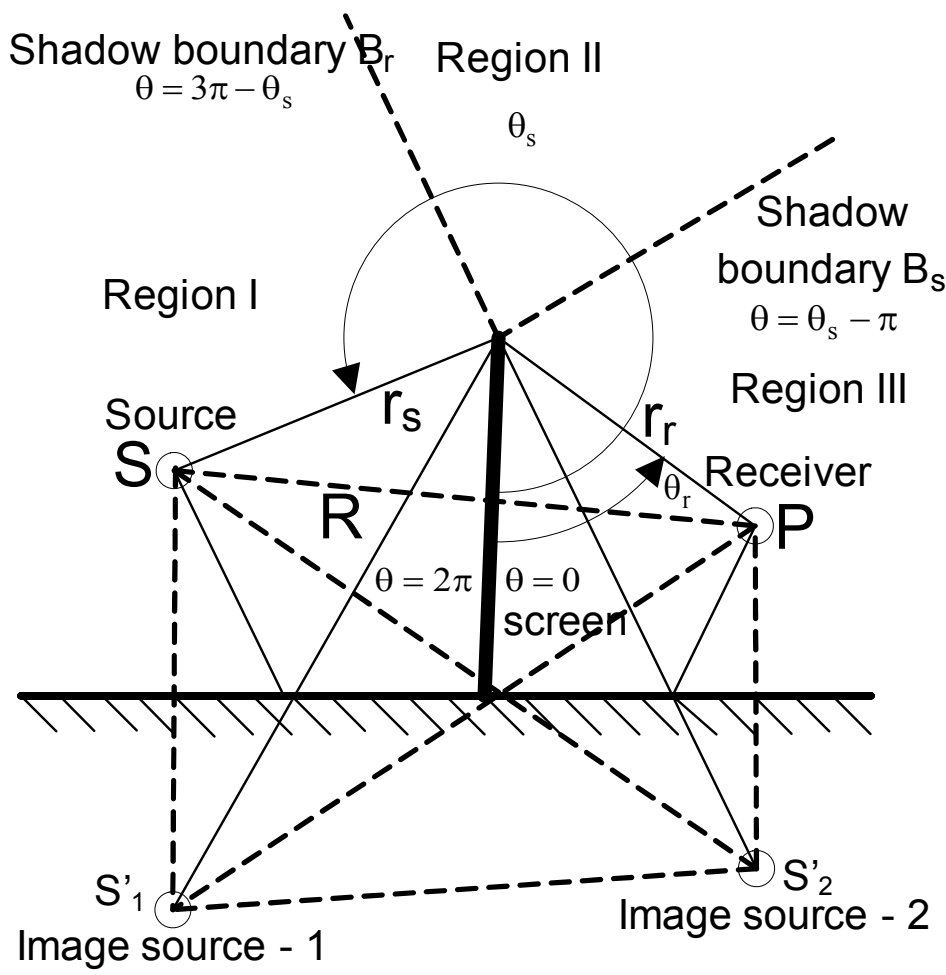

Figure 1: Geometrical relations between the sources, control point and the half plane sound barrier.

$$
\begin{aligned}
& \Delta \mathrm{L}_{\mathrm{p}}=\left\{\begin{array}{ll}
10 \lg _{10}(3+20 \mathrm{~N}) & \text { for } \mathrm{N}>-0.05 \\
0 & \text { for } \mathrm{N}<-0.05
\end{array} ; \mathrm{N}=\frac{2 \Delta \mathrm{x}}{\lambda} ;\right. \\
& \Delta \mathrm{x}=\mathrm{r}_{\mathrm{s}}+\mathrm{r}_{\mathrm{r}}-\mathrm{R} .
\end{aligned}
$$

See glossary in section 5 of this paper and Tatge [15].

Another popular formula is that of Kurze and Anderson [16], which deviates by about (2) $1.5 \mathrm{dBA}$ from Maekawa's curve for $\mathrm{N}<1$ :

$$
\Delta \mathrm{L}_{\mathrm{p}}=5+20 \lg _{10}\left[\frac{\sqrt{2 \pi \mathrm{N}}}{\tanh (\sqrt{2 \pi \mathrm{N}})}\right] \text { for } \mathrm{N}>0 .
$$

Also Yamamoto and Takagi [17] formulated four types of more accurate solutions none of which deviates from Maekawa's formula by more than $0.5 \mathrm{~dB}$. The four solution types are respectively: 


$$
\begin{aligned}
& \Delta \mathrm{L}_{\mathrm{p}}=\left\{\begin{array}{cc}
10 \lg _{10}[(1+\mathrm{G}(\mathrm{N}))(\mathrm{N}+0.3)] & \text { for } \mathrm{N}>-0.3 \\
0 & \text { for } \mathrm{N}<-0.3
\end{array} ; \mathrm{N}=\frac{2 \Delta \mathrm{x}}{\lambda} ;\right. \\
& \Delta \mathrm{x}=\mathrm{r}_{\mathrm{s}}+\mathrm{r}_{\mathrm{r}}-\mathrm{R} . \\
& \mathrm{G}(\mathrm{N})=3.621\left\{\tan \left(\frac{\mathrm{N}-0.005}{0.0145}\right)+\frac{\pi}{2}\right\}+6.165\{1-\exp [-0.205(\mathrm{~N}+0.3)]\}+2.354
\end{aligned}
$$

$$
\begin{aligned}
& \Delta \mathrm{L}_{\mathrm{p}}=\left\{\begin{array}{cl}
10 \lg _{10} \mathrm{~N}+13 & \text { for } \mathrm{N}>1 \\
5+8 \frac{\mathrm{N}}{|\mathrm{N}|^{0.55+0.143|\mathrm{~N}|}} & \text { for }-0.3<\mathrm{N}<1 ; \quad \mathrm{N}=\frac{2 \Delta \mathrm{x}}{\lambda} \\
0 & \text { for } \mathrm{N}<0.3
\end{array}\right. \\
& \Delta \mathrm{x}=\mathrm{r}_{\mathrm{s}}+\mathrm{r}_{\mathrm{r}}-\mathrm{R} \text {. } \\
& \Delta \mathrm{L}_{\mathrm{p}}=\left\{\begin{array}{cl}
10 \lg _{10} \mathrm{~N}+13 & \text { for } \mathrm{N}>1 \\
5 \pm 8|\mathrm{~N}|^{0.438} & \text { for }-0.3<\mathrm{N}<1 ; \quad \mathrm{N}=\frac{2 \Delta \mathrm{x}}{\lambda} \\
0 & \text { for } \mathrm{N}<0.3
\end{array}\right. \\
& \Delta x=r_{s}+r_{r}-R . \\
& \Delta \mathrm{L}_{\mathrm{p}}=\left\{\begin{array}{cc}
10 \lg _{10} \mathrm{~N}+13 & \text { for } \mathrm{N}>1 \\
5+9.07674 \times \sinh ^{-1}\left(|\mathrm{~N}|^{0.485}\right) & \text { for }-0.3<\mathrm{N}<1 ; \quad \mathrm{N}=\frac{2 \Delta \mathrm{x}}{\lambda} \\
0 & \text { for } \mathrm{N}<0.3
\end{array}\right. \\
& \Delta \mathrm{x}=\mathrm{r}_{\mathrm{s}}+\mathrm{r}_{\mathrm{r}}-\mathrm{R} .
\end{aligned}
$$

The efficiency of special types of barriers was also investigated. For example, a slit type barrier (Tanioku et al. [18]), a wide barrier following Pierce's model (Li and Chang-zu [19]), a barrier with a cylinder at the edge (Fujiwara and Furuta [20]) and a barrier with a multiple absorbing edge obstacle (Fujiwara and Ishikuda [21]). If properly designed, sound barriers can reduce roughly 5-15 $\mathrm{dB}(\mathrm{A})$ of the noise levels in the "shadow zone", and this may in many cases suffice to overcome the standards restrictions. Making the top of the barrier absorptive adds about $2 \mathrm{~dB}(\mathrm{~A})$ to the noise reduction.

\section{Sound barriers integration in landscape}

\subsection{Design approaches}

There are three main architectural approaches in acoustic screening design for residential areas:

One approach makes the barrier a prominent feature in the nearby environment. The second way is to use the building façade for acoustic protection of the interior, including acoustic elements (see Figures 2, 3), and a third one is to design the barrier as a part of the environment, whether natural or man-made (see Figures 4 and 5). All three types can be combined legitimately 
together in the same project. Mostly, the use of sound barriers is protection of residential areas against noise radiated from transportation, industrial premises or sports and recreation areas. In all these cases the aesthetics and view of the barrier is important on both the side of the receiver and the side of the noise source.
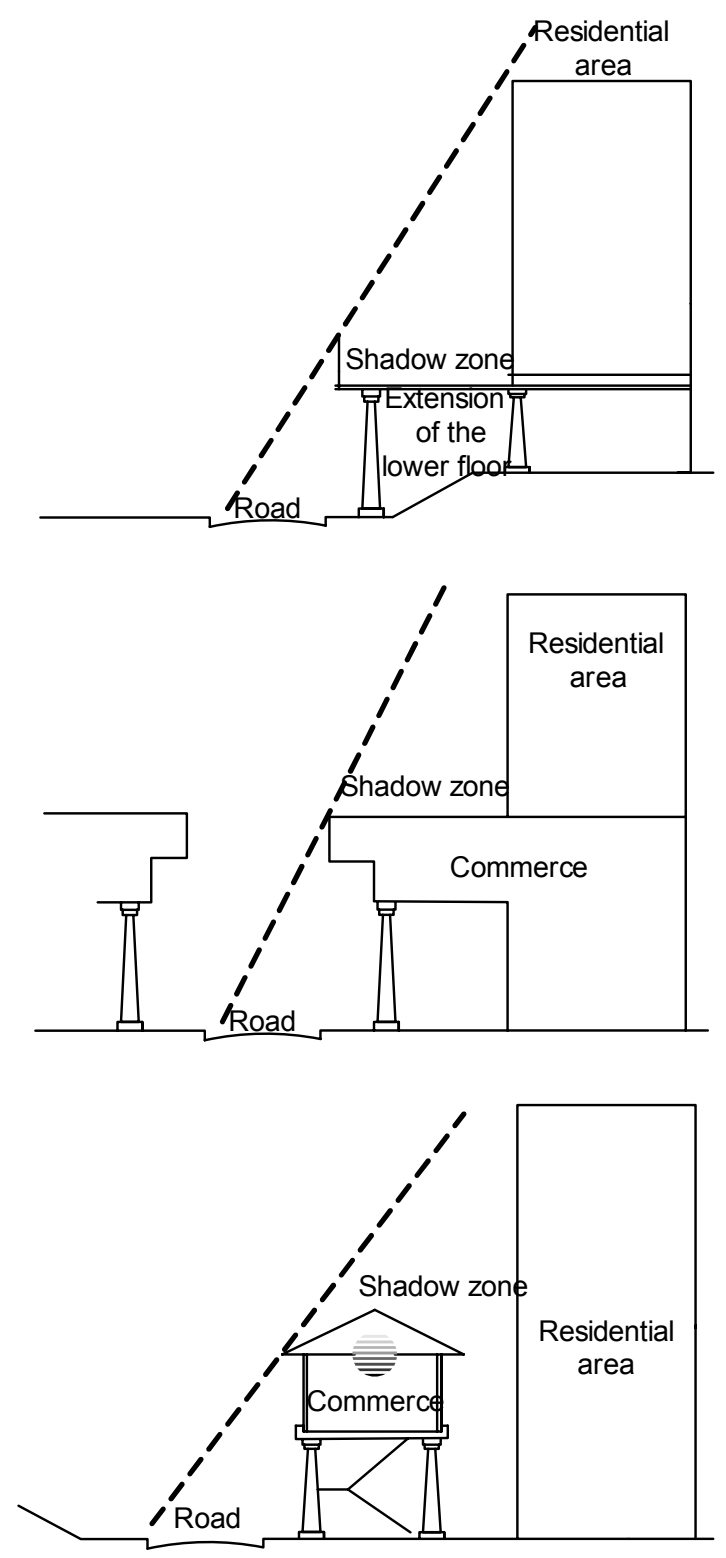

Figure 2: An acoustic screening by the building. 


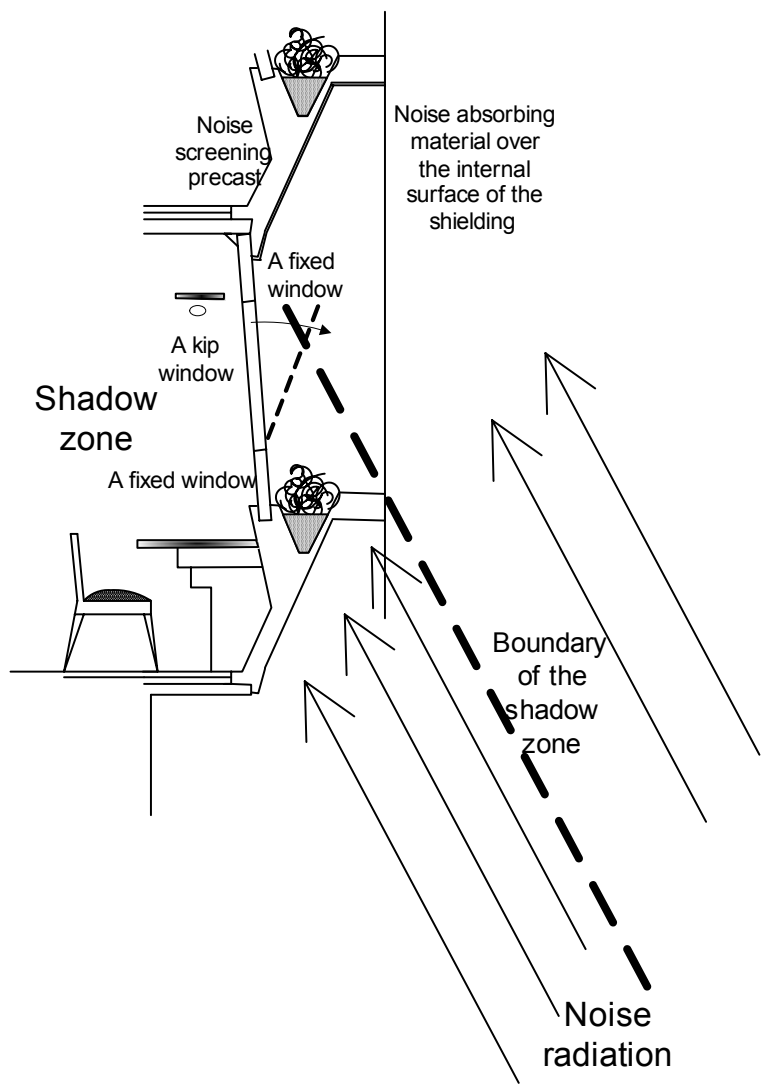

Figure 3: A detail of façade screening.

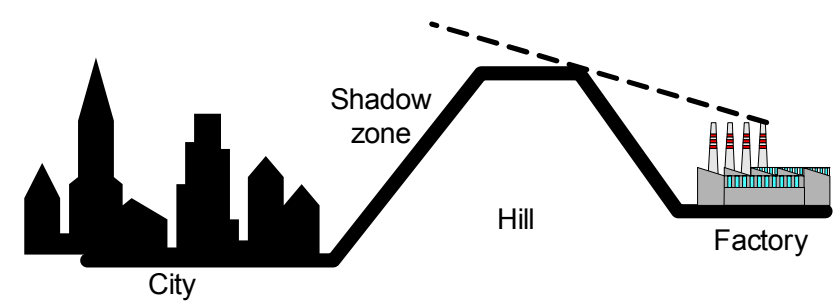

Figure 4: Topographic acoustic shadow.

When the sound barrier is prominent the shaping, materials, colours, transparency, cultural and historical considerations, texture, pattern, caps, maintenance, view and landscaping are points to be considered in the design. In the present paper we emphasize the use of sound barrier that is, as much as possible, non intrusive to the environment. 
Figure 4 illustrates a scheme of design where natural topography like a hill creates a shadow zone for a city against the noise of a nearby factory. The artificial counterpart in this case is the earth berm, mound or embankment. The deficiency of the earth berm is its wide base due to its natural slopes, which consume area. This problem can be partially solved by "cutting" the width of the slopes by steep retaining walls.

Landscape considerations in sound barrier design are shown in figure 5. A house is located a few tens of meters from a main road as shown in figure $5 \mathrm{a}$. Being exposed to heavy transportation noise, the measured levels are too high, which invites the design of a shadow zone by screening. The amount of needed noise reduction follows standard noise limits. The next step is calculation of the barrier height by using for example one of the aforementioned formulae.

One of the possible solutions is road depression, which may solve the problem, but causes a steep cut in the landscape (see figure $5 \mathrm{~b}$ ). This cut should be very long since otherwise the screening will not be effective. Another possibility is shown in figure $5 \mathrm{c}$. A thin sound barrier is built, which may have the same effect as the cut. This wall has to be also very long, or, alternatively perpendicular walls should be added along the border of the area that belongs to the house. Because of this screening, some activities can be done beyond the wall, due to its noise reduction. A combination of road depression and a thin wall barrier yields more acoustic shadow as shown in figure 5d. A road depression combined with a horizontal slab (see figure 5e) yields an effect that is similar to that of the scheme in figure $5 \mathrm{~d}$.

Finally, a solution that integrates better with the environment and is not less effective can be obtained if the house is distant enough from the road. A small slope angle created in the area in front of the house and right landscaping gives us the advantage of road depression and thin walls noise protection. It should be noted that due to the ground sound absorption, about $2-3 \mathrm{~dB}$ can be added to the noise reduction as compared with non-absorptive sound barriers of the same height.

\section{Conclusion}

Designing against noises of road and railway traffic, factories, and recreation and sports areas can be done by using sound barriers. The theoretical analysis of noise reduction by such shielding is now established, backed by a huge amount of experimental data and evidence. At this stage researchers are trying to blend active noise control in design of barriers, but this a future trend. As a consequence of the intensive development in this area, the resulting engineering tool allows for architectural and environmental considerations without any analytical burden.

The present paper illustrates how by involving architecture, the design of noise protection of residential areas can be friendly to the environment and landscaping. The additional benefit of the suggested approach is that a proper design may allow for building houses in a noisy area, still enabling living with open windows. This means allowing natural fresh air into the room through the windows, and saving artificial ventilation and air conditioning energy. 

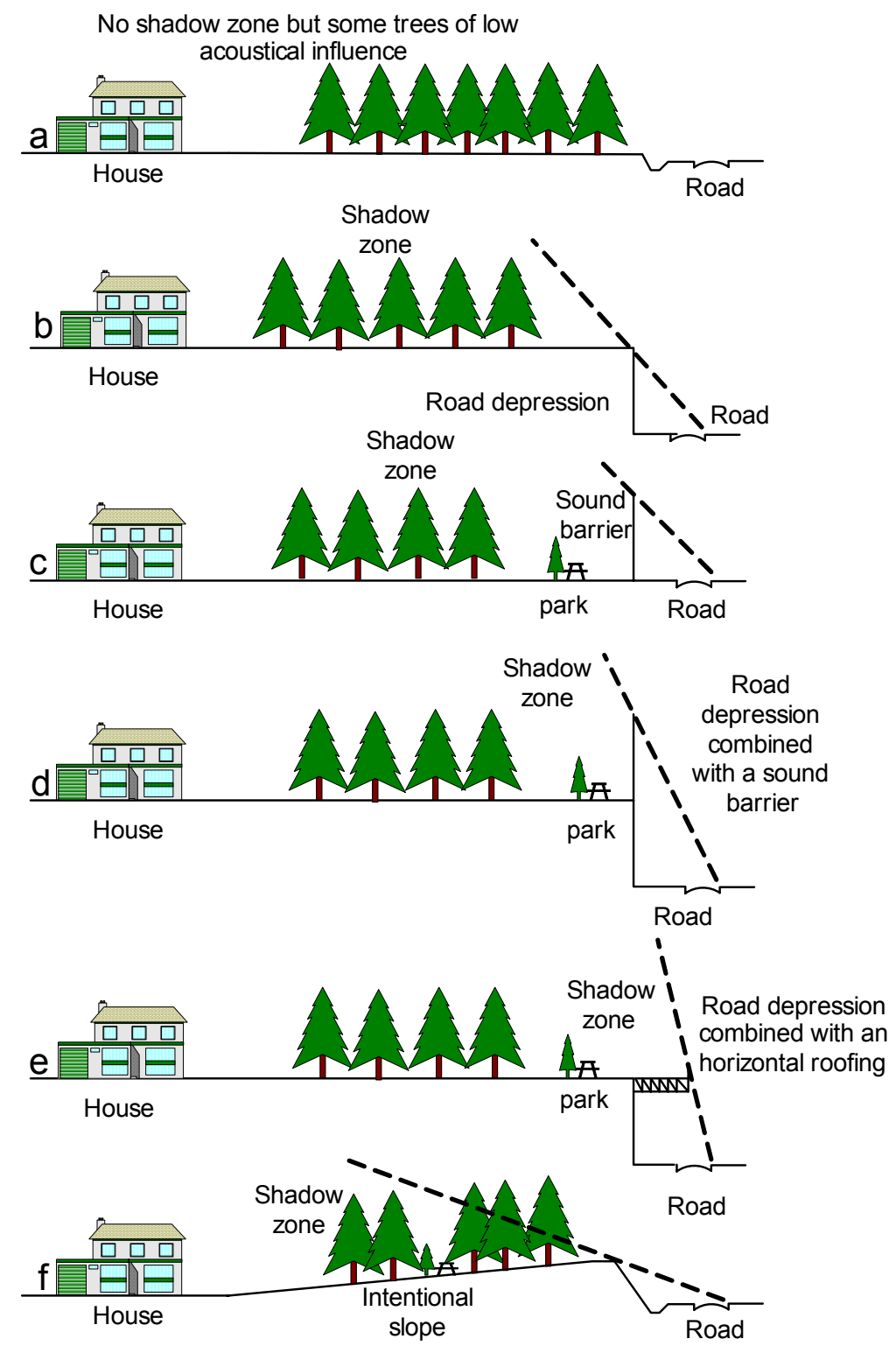

Figure 5: Landscape acoustic screening.

\section{Glossary}

$\mathrm{N}-$ Fresnel number.

$\mathrm{P}$ - control point. 
$\mathrm{R}$ - the length of the sight line, SP, $\mathrm{m}$.

$\mathrm{r}_{\mathrm{s}}$ - the distance between the source and the top of the barrier, 2-D analysis, $\mathrm{m}$.

$r_{s}$ - the distance between the control point and the top of the barrier in 2-D analysis, $\mathrm{m}$.

$\mathrm{S}$ - sound source point.

$\lambda$ - source sound wave length, $\mathrm{m}$.

$\Delta \mathrm{L}_{\mathrm{p}}$ - reduction of sound level by the screen, at the control point, $\mathrm{dBA}$.

\section{References}

[1] Sommerfeld, A., Mathematische Theorie der Diffraction. Math. Ann. 47, 1896.

[2] Tolstoy, I., Exact explicit solutions for diffraction by hard sound barriers and seamount. Jr. Acoust. Soc. Am., 85, pp. 661-669, 1989.

[3] Maekawa, Z-I, Noise reduction by screens. J. Appl. Acoust., 1, pp. 157173, 1968.

[4] Pierce, A.D., Diffraction of sound around corners and over wide barriers. Jr. Acoust. Soc. Am., 55(5), pp. 941-955, 1974.

[5] Hu, Z. \& Wong, R.L.M., Barrier insertion loss versus Fresnel number and secondary parameters. Noise Con. Engineering J. 20(1), pp. 31-36, 1983.

[6] Menounou, P., Bush-Vishniac, I.J. \& Blackstock, D., Directive line source model for sound diffracted by half planes and wedges. J. Acoust. Soc. Am., 107, pp. 2973-2986, 2000.

[7] Menounou, P., A correction to Maekawa's curve for the insertion loss behind barriers. Noise-Con 2000, ed. J.J. Van Houten, Newport Beach California, CD, 2000.

[8] Quis, D., Diffraction by half-plane: useful approximation to an exact formulation. J. sound Vib., 252, pp. 191-221, 2002.

[9] Li, K.M. \& Wong, H.Y., A review of commonly used analytical and empirical formulae for predicting sound diffracted by a thin screen. J.Appl. Acoust., 66 ,pp. 45-76, 2005.

[10] Redfearn, S.W., Some acoustical source-observer problems. Phil. Mag. 30, p. 223, 1940.

[11] Rettinger, M., Noise level reduction of barriers. Noise Control, 3(5), pp. 50-52, 1957.

[12] Rettinger, M., Noise level reduction of "depressed" freeways. Noise Control, 5(4), pp. 212-254, 1959.

[13] Rettinger, M., Acoustic Design and Noise Control. Vol. 2: Noise Control. Chemical Publishing, NY, pp.315-324, 1977.

[14] Born, M. \& Wolf, E., Principles of Optics, $4^{\text {th }}$ ed. Pergamon Press, pp. 375-386, 1970.

[15] Tatge, R.B., Bar-wall attenuation with a finite sized source. J. Acoust. Soc. Am. 53, pp.1317-1319, 1973.

[16] Kurze, U.J. \& Anderson G.S., Sound attenuation by barriers. J. Appl. Acoust. 4, pp. 35-53, 1971. 
[17] Yamamoto, K. \& Takagi, K. Expression of Maekawa's chart for computation. J. Appl. Acoust. 37, pp.75-82, 1992.

[18] Tanioku, Y., Konishi, K. \& Maekawa, Z-I, Noise reduction of a slit-type barrier by using the line integral method and full scale model measurement. Inter-Noise 87, ed. Li Pei-zi, Beijing, China, Pp. 395-398, 1987.

[19] Li, Z. \& Chang-Zu, Z., Diffraction field of traffic noise behind building along a street. Inter-Noise 87, ed. Li Pei-zi, Beijing, China, Pp. 403-406, 1987.

[20] Fujiwara, K. \& Furuta, N., Sound shielding efficiency of a barrier with a cylinder at the edge. Noise Con. Engng J. Beijing, China, pp. 5-11, 1991.

[21] Fujiwara, K. \& Ishiduka, T., Noise Shielding efficiency of a barrier with multiple absorbing edge obstacle. Inter-Noise 99, eds. J. Cuschieri, S., S. Glegg \& Y. Yong, Fort Lauderdale, Florida, pp. 451-454, 1999. 